\title{
EXPERIMENTAL EVIDENCE FOR SALTATIONAL CHROMOSOME EVOLUTION IN CALYCADENIA PAUCIFLORA GRAY (ASTERACEAE)
}

\author{
GERALD D. CARR \\ Department of Botany, University of Hawaii, 3190 Maile Wav, Honolulu, \\ Hawaii 95822, U.S.A.
}

Received 14.i.80

\section{SUMMARY}

\begin{abstract}
The fertility of the $F_{1}$ structural heterozygote formed by crossing two aneuploid chromosome races of Calycadenia pauciflora is high despite the fact they are differentiated by the equivalent of three chromosome translocations. This and the fact that ancestral and derived structural homozygotes were recovered in experimental $F_{2}$ and $F_{3}$ progenies support the hypothesis that the derived race could have originated directly from the ancestral race in nature through a single saltational event involving multiple chromosome breaks. Two individuals with structurally unique, recombined chromosomes were also recovered in the $F_{2}$ and the evolutionary potential of such products of meiosis in structural heterozygotes is considered to be significant.
\end{abstract}

\section{INTRODUCTION}

THERE have been several experimental studies documenting the existence of pairs or groups of diploid plant species differentiated by little more than chromosome alterations, of ten accompanied by aneuploidy. Calycadenia, Chaenactis, Clarkia and Crepis are just a few of the genera in which this situation is best known or more frequent. In Clarkia, Lewis (1966) referred to this process of differentiation as saltational speciation. Others have used the term quantum evolution or quantum speciation in reference to this general phenomenon (cf. Grant, 1971).

This type of chromosomal evolution requires that a new structural heterozygote pass through a "bottleneck of sterility" before the derived structural homozygote can be produced (cf. Carr, 1975). There appears to be little direct experimental evidence reported to support the plausibility of the formation of the derived structural homozygote in any of the studies on sibling species reported to date. Even in the study on Clarkia lingulata (Lewis and Roberts, 1956) where considerable experimental data were presented, parental and derived structural homozygotes apparently were not retrieved from selfed or intercrossed $F_{1}$ structural heterozygotes.

This paper provides experimental evidence that structural heterozygotes formed by experimental hybridisation of aneuploid races of Calycadenia pauciflora are fairly fertile and that ancestral and derived structural homozygotes can be retrieved from the $F_{2}$ and later progenies with relative ease. Thus, it appears quite plausible that the derived race originated in nature directly from the ancestral race and that the new structural homozygote may have been formed in the progeny of hybridising heterozygotes in the same manner as accomplished experimentally. 
Calycadenia pauciflora is an annual, self-incompatible species in the tarweed subtribe of the Heliantheae (Asteraceae). It comprises four homoploid chromosome races $(n=6)$ differentiated chiefly by translocations and one aneuploid race $(n=5)$ differentiated from the others by chromosome number and structure (Carr, 1975). The latter race was designated Pauciflora whereas its nearest relative and probable ancestor was designated Tehama. The origin of race Pauciflora from race Tehama is the subject of this paper.

\section{MATERIALS AND METHODS}

Structural $\mathrm{F}_{1}$ hybrids were produced by crossing individuals of Calycadenia pauciflora of race Tehama (Carr 664) with those from race Pauciflora (Carr 607). These structurally heterozygous $F_{1}$ 's were intercrossed to produce an $\mathrm{F}_{2}$ progeny. Additional crosses between two structurally heterozygous $F_{2}$ individuals yielded an $F_{3}$ progeny. Each of two 5-paired structural homozygotes of the Pauciflora type in the $F_{2}$ was backcrossed to one of two natural populations (Carr 607 and Carr 646) of race Pauciflora. Similarly, a structural homozygote of the putatively ancestral 6-paired type in the $F_{2}$ was backcrossed to an individual from a natural population (Carr 743) of race Tehama (see Carr, 1975, for additional methodology and data on origin).

Floral buds for meiotic analysis of all progenies were fixed and stored in a modified Carnoy's solution of chloroform, absolute ethanol and glacial acetic acid $(6: 3: 1 \mathrm{v}: \mathrm{v})$. Anthers were squashed in acetocarmine and mounted according to Beeks' Permanent Squash Method (Beeks, 1955).

For the production of mitotic karyotypes of the chromosome races, root tips were pretreated in $p$-dichlorobenzene at $4^{\circ} \mathrm{C}$ for $5 \frac{1}{2}$ hours prior to their fixation in Carnoy's fluid. The root tips were hydrolysed in a mixture of concentrated $\mathrm{HCl}$ and 95 per cent ethanol $(1: 1 \mathrm{v}: \mathrm{v})$ for about 90 seconds, macerated in acetocarmine and mounted as outlined above. Pollen fertility of all progenies was assessed by the stainability in cotton blue of 500 grains from each individual.

\section{Results}

The karyotypes of races Pauciflora and Tehama of Calycadenia pauciflora differ qualitatively and quantitatively (fig. 1). The maximum meiotic chromosome pairing configuration observed in $F_{1}$ hybrids is a complex multiple of five chromosomes and three bivalents (fig. 2). Moreover, the distribution of nucleolar organising chromosomes (cf. figs. 2, 3 ) indicates that a maximum multiple of seven chromosomes is possible, but probably is extremely rare because of the suppression of pairing in nucleolar organising chromosome arms, especially in small translocated segments (cf. Kyhos, 1965). In spite of considerable structural heterozygosity the $F_{1}$ hybrids had the relatively high mean pollen stainability of 43 per cent (table 1).

The $F_{2}$ and $F_{3}$ individuals derived from crossing $F_{1}$ heterozygotes can be divided into four major categories: (1) heterozygotes, (2) Tehama type, (3) Pauciflora type, and (4) chromosomal recombinants (tables 1,2). The $15 \mathrm{~F}_{2}$ and $F_{3}$ heterozygotes had an average pollen stainability of 41 per cent (tables 
1,2). They were identified by their possession of the $F_{1}$ chromosome pairing configuration. The plants allocated to Tehama and Pauciflora had six and five pairs of chromosomes, respectively, and averaged high pollen stainability (tables 1,2). The plants considered recombinants either possessed extra chromosomes or had one or more reconstituted chromosomes, probably resulting from cross-over events in the structural heterozygote. As a class the pollen stainabilities of recombinants were intermediate (tables 1,2).

TABLE 1

Cytological characteristics of the $F_{1}, F_{2}, F_{3}$ and backcross progenies of the cross Pauciflora $\times$ Tehama

\begin{tabular}{|c|c|c|c|c|}
\hline Individual & $\begin{array}{c}\text { Pollen } \\
\text { stainability } \\
(\%)\end{array}$ & $\begin{array}{c}\text { Chromosome } \\
\text { no. }(2 n)\end{array}$ & $\begin{array}{c}\text { Pairing } \\
\text { configuration }\end{array}$ & Designation \\
\hline$F_{1}^{*}$ & 43 & 11 & $\mathrm{Ch}_{5}+3_{11} \dagger$ & Heterozygote \\
\hline $\mathrm{F}_{2} \mathrm{a}$ & 42 & 11 & $\mathrm{Ch}_{5}+3_{\mathrm{II}}^{\dagger}$ & Heterozygote \\
\hline$F_{2} b$ & 43 & 11 & $\mathrm{Ch}_{5}+3_{\mathrm{II}}^{\dagger}$ & Heterozygote \\
\hline $\mathrm{F}_{2} \mathrm{c}$ & 25 & 11 & $\mathrm{Ch}_{5}+3_{\mathrm{II}}^{\dagger}$ & Heterozygote \\
\hline$F_{2} \mathrm{~d}$ & 42 & 11 & $\mathrm{Ch}_{5}+3_{\mathrm{II}^{\dagger}, \S}$ & Recombinant \\
\hline $\mathrm{F}_{2} \mathrm{e}$ & 88 & 10 & $5_{11}{ }^{* *}$ & Pauciflora \\
\hline$F_{2} f$ & 94 & 10 & $5_{I I} * *$ & Pauciflora \\
\hline$F_{2} g$ & 55 & 11 & $\mathrm{Ch}_{5}+3_{11}^{\dagger}$ & Heterozygote \\
\hline $\mathrm{F}_{2} \mathrm{~h}$ & 70 & 10 & $5_{11} * *$ & Pauciflora \\
\hline $\mathrm{F}_{2} \mathrm{i}$ & 83 & 12 & $6_{11}$ & Tehama \\
\hline$F_{2} j$ & 85 & 12 & $6_{11}$ & Tehama \\
\hline $\mathrm{F}_{2} \mathrm{k}$ & 33 & 13 & $\mathrm{Ch}_{3}+5_{11} * *$ & Recombinant \\
\hline$F_{2} 1$ & 82 & 10 & $\mathrm{Ch}_{4}+3_{11} \S$ & Recombinant \\
\hline $\mathrm{F}_{3} \mathrm{a}$ & 46 & 12 & $6_{11}$ & Tehama \\
\hline$F_{3} b$ & - & 11 & $\mathrm{Ch}_{5}+3_{\mathrm{II}}^{\dagger}$ & Heterozygote \\
\hline $\mathrm{F}_{3} \mathrm{C}$ & 63 & 11 & $\mathrm{Ch}_{3}+4_{11} * *$ & Recombinant \\
\hline$F_{3} d$ & 100 & 10 & $5_{11} * *$ & Pauciflora \\
\hline $\mathrm{F}_{3} \mathrm{e}$ & 23 & 11 & $\mathrm{Ch}_{5}+3_{\mathrm{II}}^{\dagger}$ & Heterozygote \\
\hline $\mathrm{F}_{3} \mathrm{f}$ & - & 11 & $\mathrm{Ch}_{3}+4_{11} * *$ & Recombinant \\
\hline $\mathrm{F}_{3} \mathrm{~g}$ & 48 & 11 & $\mathrm{Ch}_{5}+3_{\mathrm{II}}^{\dagger}$ & Heterozygote \\
\hline $\mathrm{F}_{3} \mathrm{~h}$ & 77 & 11 & $\mathrm{Ch}_{3}+4_{11} * *$ & Recombinant \\
\hline $\mathrm{F}_{3} \mathrm{i}$ & 38 & 11 & $\mathrm{Ch}_{5}+3_{\mathrm{II}^{\dagger}}$ & Heterozygote \\
\hline$F_{3} j$ & 76 & 10 & $5_{11}{ }^{* *}$ & Pauciflora \\
\hline$F_{3} k$ & 98 & 10 & $5_{11} * *$ & Pauciflora \\
\hline$F_{3} 1$ & 67 & 11 & $\mathrm{Ch}_{5}+3_{11}^{\dagger}$ & Heterozygote \\
\hline $\mathrm{F}_{3} \mathrm{~m}$ & 29 & 11 & $\mathrm{Ch}_{5}+3_{\mathrm{II}}^{\dagger}$ & Heterozygote \\
\hline $\mathrm{F}_{3} \mathrm{n}$ & 36 & 12 & $\mathrm{Ch}_{3}+4 \mathrm{II}^{\dagger}$ & Recombinant \\
\hline $\mathrm{F}_{3} \mathrm{O}$ & 94 & 12 & $6_{11}$ & Tehama \\
\hline$F_{3} p$ & 23 & 11 & $\mathrm{Ch}_{5}+3_{\mathrm{II}}^{\dagger}$ & Heterozygote \\
\hline $\mathrm{F}_{3} \mathrm{q}$ & 82 & 12 & $6_{\mathrm{II}}$ & Tehama \\
\hline $\mathrm{F}_{3} \mathrm{r}$ & 51 & 11 & $\mathrm{Ch}_{5}+3_{\mathrm{II}}^{\dagger}$ & Heterozygote \\
\hline $\mathrm{F}_{3} \mathrm{~s}$ & 31 & 12 & $6_{\mathrm{II}}$ & Tehama \\
\hline$F_{3} t$ & 39 & 11 & $\mathrm{Ch}_{5}+3_{\mathrm{nI}} \dagger$ & Heterozygote \\
\hline $\mathrm{F}_{3} \mathrm{u}$ & 43 & 11 & $\mathrm{Ch}_{5}+3_{\mathrm{II}}^{\dagger}$ & Heterozygote \\
\hline $\mathrm{F}_{3} \mathrm{~V}$ & 44 & 11 & $\mathrm{Ch}_{5}+3_{\mathrm{II}}^{\dagger}$ & Heterozygote \\
\hline Pauciflora $607 \times \mathrm{F}_{2} \mathrm{e} \dagger$ & $>90$ & 10 & $5_{I I} * *$ & Pauciflora \\
\hline Pauciflora $646 \times \mathrm{F}_{2} \mathrm{e} \S \S$ & $>90$ & 10 & $5_{I I} * *$ & Pauciflora \\
\hline $\mathrm{F}_{2} \mathrm{j} \times$ Tehama 743 & 98 & 12 & $6_{11}$ & Tehama \\
\hline \multicolumn{5}{|c|}{$\begin{array}{l}\text { * Data represent five individuals. } \\
\text { † Unequal ring pair present (see text). } \\
\text { § Recombined chromosome present (see text). } \\
\text { ** Large metacentric ring pair from Pauciflora present (see text). } \\
\text { †† Data represent three individuals. }\end{array}$} \\
\hline
\end{tabular}


One of the recombinants in the $F_{2}$ progeny (table $1, F_{2} d$ ) was of special interest because of the fact that it contained a structurally unique chromosome apparently resulting from chromatid exchange during meiosis in the $F_{1}$. Each arm of the large metacentric fusion chromosome from race Pauciflora (fig. 1; cf. Carr, 1975) is distally homologous with each arm of a much smaller chromosome from race Tehama which at meiosis in the $F_{1}$ leads to the formation of an unequal ring (fig. 3, $Q R$ ). Additionally, the large metacentric has a small proximal euchromatic region that is homologous with the terminal portion of a second chromosome from race Tehama

TABLE 2

Summary of $F_{2}$ and $F_{3}$ products of the cross Pauciflora $\times$ Tehama

$\begin{array}{lcc}\text { Designation } & \begin{array}{c}\text { Number of } \\ \text { individuals }\end{array} & \begin{array}{c}\text { Pollen } \\ \text { stainability }(\%)\end{array} \\ \text { Pauciflora } & 6 & 88 \\ \text { Tehama } & 6 & 70 \\ \text { Heterozygotes } & 15 & 41 \\ \text { Recombinants } & 7 & 56\end{array}$

which leads to the maximum observed association of five chromosomes in the $\mathrm{F}_{1}$ by joining the unequal ring $(Q R)$ to the branched chain of three $\left(A B C\right.$, cf. figs. 2, 3). Apparently chromatid exchange in the $\mathrm{F}_{1}$ has resulted in adding to this second chromosome the portion of the arm of the large metacentric chromosome distal to the point of exchange, thus creating a chromosome of a new constitution that does not exist in either race Tehama or Pauciflora. This alteration is indicated by the additional block of chromatin in one of the unterminalised arms of the chain of three (cf. figs. 3, 4) and by the size of the unterminalised arm of this chromosome when paired to the proximal region of the metacentric chromosome of the unequal ring (fig. 5). Increased homology between the reconstituted chromosome and the large metacentric chromosome is also suggested by at least a 20 -fold increase in the frequency of occurrence of the maximum observed association of 5 in $\mathrm{F}_{2} \mathrm{~d}$ over that in $\mathrm{F}_{1}$ individuals. Moreover, as might be predicted this recombinant chromosome can pair with the small chromosome of the unequal ring (fig. 6), whereas this new chromosome's counterpart in the chain of three of the $F_{1}$ exhibits no such homology. This $\mathrm{F}_{2}$ recombinant had a pollen stainability of 42 per cent. A second plant $\left(\mathrm{F}_{2} \mathrm{l}\right)$ with 82 per cent stainable pollen also exhibited a unique meiotic configuration presumably due to the presence of one or more structurally altered chromosomes. In this case, however, the nature and origin of the oddity could not be satisfactorily demonstrated.

The one $F_{2}$ individual $\left(F_{2} j\right)$ designated Tehama has a pollen stainability of 85 per cent. It was backcrossed to an individual of race Tehama from the field and the single individual in the backcross progeny had a pollen stainability of 98 per cent (table 1$)$. The two $F_{2}$ individuals $\left(F_{2}\right.$ e and $\left.F_{2} h\right)$ designated Pauciflora had pollen stainabilities of 88 and 70 per cent, respectively (table 1). These were backcrossed to individuals of race Pauciflora from the field and five individuals in two backcross progenies had an average pollen stainability greater than 90 per cent (table 1). 
Plate II

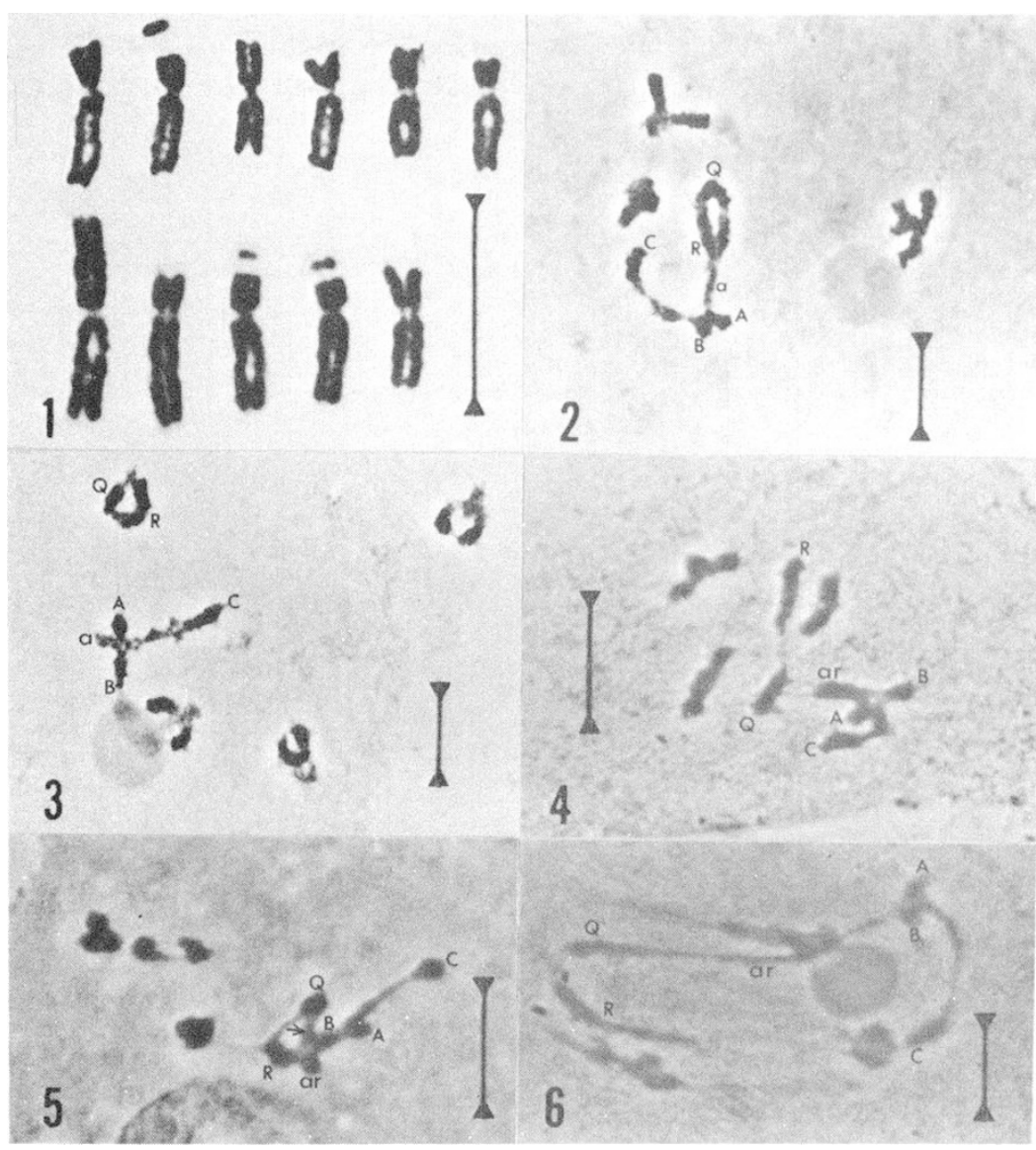

FIG. 1.-Mitotic haploid complement of Calycadenia pauciflora, race Tehama $(n=6)$ above, race Pauciflora $(n=5)$ below.

FIGs. 2-6.-Meiosis in $F_{1}$ and $F_{2}$ hybrids between races Tehama and Pauciflora of Calycadenia pauciflora. 2: $\mathrm{F}_{1}$, maximum observed configuration, note chain of five $(A B C Q R)$ involving unequal ring $(Q R)$. 3: $\mathrm{F}_{1}$, modal configuration, note unequal ring $(Q R)$ and unterminalised arm (a) of chromosome $(A)$ of chain of three $(A B C)$. 4: Recombinant individual $\mathrm{F}_{2} \mathrm{~d}$, note unequal pair $(Q R)$ and large unterminalised arm (ar) of chromosome $(A)$ of chain of three $(A B C) .5: \mathrm{F}_{2} \mathrm{~d}$, note chain of five $(A B C Q R)$, compare unterminalised arm of recombined chromosome (ar) and portion of large metacentric chromosome ( $R$, arrow) distal to point of exchange. $6: F_{2} d$, note pairing between recombined chromosome $(a r)$ of the chain of three $(A B C)$ and the small chromosome $(Q)$ of the potential unequal ring $(Q R)$ [resultant chain of five $(A B C Q R)$ is superimposed on nucleolar organising pair] (bar $=10 \mu)$. 

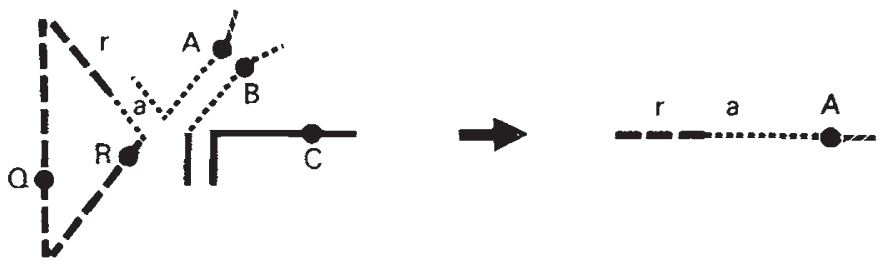

FIG. 7.-Simplified schematic interpretation of the chain of five chromosomes in the $F_{1}$ hybrid between races Pauciflora and Tehama of Calycadenia pauciflora and the possible mode of origin of a structurally unique chromosome in the $F_{2}$. The altered chromosome $A$ on the right could have been generated by a chiasmatal exchange in the proximal portion of the region designated $a$ in the chain of five on the left. This structural arrangement would account for all of the observed meiotic abnormalities in the $F_{2}$ structural heterozygote possessing this chromosome $\left(\mathrm{F}_{2} \mathrm{~d}\right.$, see text).

\section{Discussion}

The results suggest that race Pauciflora is differentiated from Tehama by the equivalent of at least three chromosome translocations and the loss of one centromere, yet $F_{1}$ hybrids have a mean fertility of over 40 per cent. The fact that one pair of chromosomes is heterozygous for nucleolar organisation and that one chromosome of the chain of five organises a nucleolus (cf. figs. 2,3 ) indicates that one of the translocations includes a nucleolar organising region. This may involve a very small segment of heterochromatin including a nucleolar organising region and possibly has little effect on fertility. A point of considerable interest is that the large metacentric fusion chromosome of race Pauciflora confers a greater chance of viability to gametes and zygotes containing it. This is supported by the fact that at least 27 of the $34 \mathrm{~F}_{2}$ and $\mathrm{F}_{3}$ individuals (table 1) possessed this chromosome in single or double dose.

In any event, the fertility of the heterozygote and the experimental evidence suggest that race Pauciflora could have originated as a heterozygote by a saltational event including multiple breaks and fusions involving three or more chromosomes of race Tehama. This heterozygote would have been forced to backcross to race Tehama in order to leave progeny. Of these, about half would be heterozygotes and about half would be race Tehama. As demonstrated experimentally, cross compatible heterozygotes could then produce some individuals homozygous for the Pauciflora genome.

In Clarkia, Lewis $(1962,1973)$ has suggested that catastrophic selection followed by inbreeding, extensive chromosome breakage, chance elimination of the parental homozygotes, and chance formation of homozygous combinations of rearranged chromosomes have played a prominent role in the formation of diploid neospecies. I believe that self-compatibility and the lack of seed storage in Clarkia make these hypotheses tenable.

However, an important aspect of race formation in the self-incompatible annual plants in this study is that a newly arisen structural heterozygote is tied to the ancestral race for reproduction. Furthermore, because of seed storage, the heterozygote and the new structural homozygote remain in contact with the ancestral structural homozygote regardless of the action of short term catastrophic selection. In fact we have evidence (Carr and Carr, 
in preparation) that at least one interbreeding population of Calycadenia ciliosa contains representatives of three distinct cytodemes. Under these circumstances it is difficult to ignore the importance of natural selection in the evolution and maintenance of chromosome races in these and other species with similar breeding systems, e.g., in Chaenactis, Coreopsis, Haplopappus and Holocarpha, to name a few.

One aspect of meiosis of structural heterozygotes that may have special evolutionary significance is the formation of structurally unique chromosomes as a result of chromatid exchange, as experimentally demonstrated here. Such chromosomes may have duplications for segments containing especially advantageous gene combinations and could be preserved and fixed in the homozygous condition by natural selection. According to Lewis (1966) a similar kind of chromosome was added to the genome of Clarkia biloba ssp. australis to produce the diploid neospecies Clarkia lingulata. The structurally new, recombined chromosome recovered in one of the $\mathrm{F}_{2}$ individuals of the Calycadenia pauciflora heterozygote described herein contained duplicated and translocated segments which conferred to it partial homology with at least three or possibly four other chromosomes of the genome. Since the fertility of that plant was high ( 42 per cent stainable pollen), it is likely that the recombined chromosome could have been fixed in the homozygous state in later progenies. Such a chromosome, carrying the appropriate genes, might have considerable evolutionary importance in nature.

Acknowledgements.--I would like to thank Dr Donald W. Kyhos for his helpful comments on an early draft of this paper.

\section{REFERENCES}

BEEKS, R. M. 1955. Improvements in the squash technique for plant chromosomes. El Aliso, 13, 131-134.

CARR, G. D. 1975. Chromosome evolution and aneuploid reduction in Calycadenia pauciflora (Asteraceae). Evolution, 29, 681-699.

GRANT, V. 1971. Plant Speciation. Columbia University Press, New York.

KYHOS, D. W. 1965. The independent aneuploid origin of two species of Chaenactis (Compositae) from a common ancestor. Evolution, 19, 26-43.

LEWIS, F, H. 1962. Catastrophic selection as a factor in speciation. Evolution, 16, 257-271. LEWIS, F, H. 1966. Speciation in flowering plants. Science, 152, 167-172.

LEWIS, F. H. 1973. The origin of diploid neospecies in Clarkia. Amer. Nat., 107, 161-170. LEWIS, F. H., AND ROBERTS, M. R. 1956. The origin of Clarkia lingulata. Evolution, 10, 126-138. 